\title{
Ambient Ozone Exposure in Czech Forests: A GIS-Based Approach to Spatial Distribution Assessment
}

\author{
I. Hůnová, ${ }^{1}$ J. Horálek, ${ }^{1}$ M. Schreiberová, ${ }^{1}$ and M. Zapletal ${ }^{2,3}$ \\ ${ }^{1}$ Ambient Air Quality Department, Czech Hydrometeorological Institute, 14306 Prague, Czech Republic \\ ${ }^{2}$ Faculty of Philosophy and Science, Silesian University at Opava, 74601 Opava, Czech Republic \\ ${ }^{3}$ Ekotoxa s.r.o.-Centre for Environment and Land Assessment, 74601 Opava, Czech Republic
}

Correspondence should be addressed to I. Hůnová, hunova@chmi.cz

Received 31 October 2011; Accepted 8 December 2011

Academic Editor: Shaibal Mukerjee

Copyright () 2012 I. Hůnová et al. This is an open access article distributed under the Creative Commons Attribution License, which permits unrestricted use, distribution, and reproduction in any medium, provided the original work is properly cited.

\begin{abstract}
Ambient ozone $\left(\mathrm{O}_{3}\right)$ is an important phytotoxic pollutant, and detailed knowledge of its spatial distribution is becoming increasingly important. The aim of the paper is to compare different spatial interpolation techniques and to recommend the best approach for producing a reliable map for $\mathrm{O}_{3}$ with respect to its phytotoxic potential. For evaluation we used real-time ambient $\mathrm{O}_{3}$ concentrations measured by UV absorbance from 24 Czech rural sites in the 2007 and 2008 vegetation seasons. We considered eleven approaches for spatial interpolation used for the development of maps for mean vegetation season $\mathrm{O}_{3}$ concentrations and the AOT40F exposure index for forests. The uncertainty of maps was assessed by cross-validation analysis. The root mean square error (RMSE) of the map was used as a criterion. Our results indicate that the optimal interpolation approach is linear regression of $\mathrm{O}_{3}$ data and altitude with subsequent interpolation of its residuals by ordinary kriging. The relative uncertainty of the map of $\mathrm{O}_{3}$ mean for the vegetation season is less than $10 \%$, using the optimal method as for both explored years, and this is a very acceptable value. In the case of AOT40F, however, the relative uncertainty of the map is notably worse, reaching nearly $20 \%$ in both examined years.
\end{abstract}

\section{Introduction}

Ambient ozone $\left(\mathrm{O}_{3}\right)$ is a widely studied air pollutant [1]. Due to its unsaturated chemical structure, it is highly reactive and contributes to the oxidative power of atmosphere, essential for scavenging many pollutants from the atmosphere [2]. It has important negative impacts on both human health and the environment as acknowledged in numerous studies [3]. Moreover, due to its absorption-radiation abilities, $\mathrm{O}_{3}$ is an important greenhouse gas $[4,5]$, and there are significant interactions between $\mathrm{O}_{3}$ and climate change [6].

Current ambient $\mathrm{O}_{3}$ levels have increased by approximately two times as compared to those measured over a century ago [7]. Although the magnitude and origin of the hemispheric $\mathrm{O}_{3}$ trends are still not completely understood [8], there are indications that background $\mathrm{O}_{3}$ levels over the midlatitudes of the Northern Hemisphere have continued to rise over the past three decades within the range of approximately $0.5-2 \%$ per year [9]. A significant contribution to $\mathrm{O}_{3}$ levels both in Europe and North America originates in East Asia as a result of its dynamic development regarding population growth and increased fossil fuel consumption [10].

For the above reasons, the detailed knowledge of spatial distribution of ambient $\mathrm{O}_{3}$ levels is becoming increasingly important. To develop a reliable, accurate, and continuous air pollutant surface predicting the values at locations without measurements is an essential task which we frequently encounter in environmental and health-related studies. This benefit of $\mathrm{O}_{3}$ mapping stands out when viewed alongside the increasingly limited financial resources available for costly ambient air quality monitoring networks.

There are a wide range of techniques available for spatial interpolation, the advantages and limitations of which are widely discussed in the scientific literature [11]. In principle these techniques are classified as deterministic (the nearest neighbor and polynomial regression) or stochastic (geostatistical approaches as kriging and cokriging). The difference between these two is that the geostatistical methods use the 
spatial correlation structure and allow a prediction variability estimate to assess, under certain conditions, prediction accuracy. In between the deterministic and stochastic methods, there are a wide range of radial basis functions or splines.

The quality of maps of air pollution depends mainly on the quality of the input data measured at the stations, on the number of measuring sites, and also on their spatial distribution $[12,13]$. Air pollution measurements, particularly those from online permanent monitoring used in routine monitoring networks, are very costly and so the number of sites is generally very limited. The number of required sites depends obviously on the type of air pollutant and on the representativeness of the measuring site. The representativeness is closely related to proximity of emission sources and topography; more stations are needed in complex terrain in contrast to flat [14]. When developing a surface for pollutants with high spatial variability (due to the importance of their local emission sources), for example, PM, benzo(a)pyrene, or toxic metals, more sites are needed. In contrast, pollutants like $\mathrm{O}_{3}$, with a more regional character, depending mostly on regional phenomena such as meteorology and long-range or regional air pollution transport need a less-dense monitoring network.

Maps of ambient $\mathrm{O}_{3}$, in context of its impacts on environment in rural areas, produced by different approaches were published for different regions: United Kingdom [15], Sierra Nevada in California [16-18], and the Carpathians in Europe [19]. Across the EU, mapping of background $\mathrm{O}_{3}$ at a fine spatial scale $(1 \times 1 \mathrm{~km})$ was carried out [20], as well as mapping of exposure index AOT40 at $2 \times 2 \mathrm{~km}$ grid resolution [21, 22]. Across the Czech Republic, the method of [15] was applied for ozone deposition mapping [23].

In the Czech Republic (CR), ambient $\mathrm{O}_{3}$ levels are elevated $[24,25]$, limit values over vast regions are frequently exceeded, and phytotoxic potential is high [26-28]. The aim of this paper is to compare the different spatial interpolation techniques and to recommend the optimal approach for producing a reliable map of $\mathrm{O}_{3}$ with respect to its phytotoxic potential.

\section{Methods}

2.1. Ambient Ozone Data. We used real-time $\mathrm{O}_{3}$ levels measured at sites in the nationwide air quality monitoring network by UV absorbance, a reference method as declared by the EC [29]. The ozone analyzers used were the Thermo Environmental Instruments (TEI), M49. The samplers were placed ca $2 \mathrm{~m}$ above ground. Standard procedures for quality control and quality assurance [29] were applied. We considered $\mathrm{O}_{3}$ seasonal means (April-September) and the exposure index AOT40 for forests-AOT40F [30], calculated according to [31]. The input data were $1 \mathrm{~h}$ mean concentrations. Data capture required for calculations of seasonal means was $75 \%$. The AOT40 index as a cumulative variable is very sensitive to the quality of measured data [32, 33] and obviously also to missing values. More stringent requirements are, thus, needed for calculation of AOT40 as compared to the seasonal mean. In cases when we had less than $90 \%$ of hourly $\mathrm{O}_{3}$ concentrations for the period of April-September for calculating the AOT40F, we corrected it according to [34] so as to prevent underestimation of the $\mathrm{O}_{3}$ exposure.

With respect to the aim of this study to assess $\mathrm{O}_{3}$ exposure for forests, urban sites were not considered. From a total of 55 sites monitoring real-time $\mathrm{O}_{3}$ concentrations across the $\mathrm{CR}$, we accounted only for rural sites as specified by EoI [35]. The rural sites according to EoI are the sites with no important emission sources nearby and which are assumed to be affected only by long-range or regional air pollution transport. Thus, the representativeness of such sites is considerable, mostly in tens to hundreds of kms. The selection of sites resulted in 24 rural sites distributed unevenly across the CR (Figure 1), with more sites at border mountain areas as compared to the interior of the country. Considering that the area of the CR is $79000 \mathrm{~km}^{2}$, the sampling density was approximately one monitor per $3292 \mathrm{~km}^{2}$.

2.2. Spatial Interpolation. Maps for mean vegetation season $\mathrm{O}_{3}$ concentrations and for exposure index AOT40F for forests were prepared. For spatial interpolation, we used 24 rural sites run by the CHMI. In addition to the Czech sites, we also used data from selected measuring sites in Germany and Poland to improve the interpolation near border areas (Figure 1). Measuring sites in Slovakia are too distant so they cannot be used. Data from Austrian sites situated near the border were not available. The maps were prepared using ArcGIS Geostatistical Analyst [36] on a grid of $1 \times 1 \mathrm{~km}$ resolution. A $25 \mathrm{~m}$ resolution DEM was used.

For spatial interpolation, eleven methods were used (Table 1). These methods are adequately referenced in scientific literature, so we comment on them only very briefly. In principle, we use three different interpolation methods using measured data only and two basic methods which combine measured and supplementary data, with four subvariants.

\subsubsection{Interpolation Methods Using Measured Data Only}

(A) Inverse Distance Weighted Method. The inverse distance weighted method (IDW) is likely to be the most frequently used deterministic method [37]. For interpolation we used

$$
\hat{Z}\left(s_{0}\right)=\frac{\sum_{i=1}^{n} Z\left(s_{i}\right) / d_{0 i}^{k}}{\sum_{i=1}^{n} 1 / d_{0 i}^{k}},
$$

where $\hat{Z}\left(s_{0}\right)$ is the interpolated value of concentration in the point $s_{0}, Z\left(s_{\mathrm{i}}\right)$ is the measured value of concentration in the $i$ th point, $i=1, \ldots, n, d_{0 i}$ is the distance between the interpolated point and the $i$ th point with measurement, and $n$ is the number of sites used for interpolation.

(B) Radial Basis Functions Method. Radial basis functions (RBF) interpolate the measured value while minimizing the total curvature of the surface. The interpolation is described by

$$
\hat{Z}\left(s_{0}\right)=\sum_{i=1}^{n} w_{i} \cdot \Phi\left(d_{0 i}\right)+w_{n+1},
$$




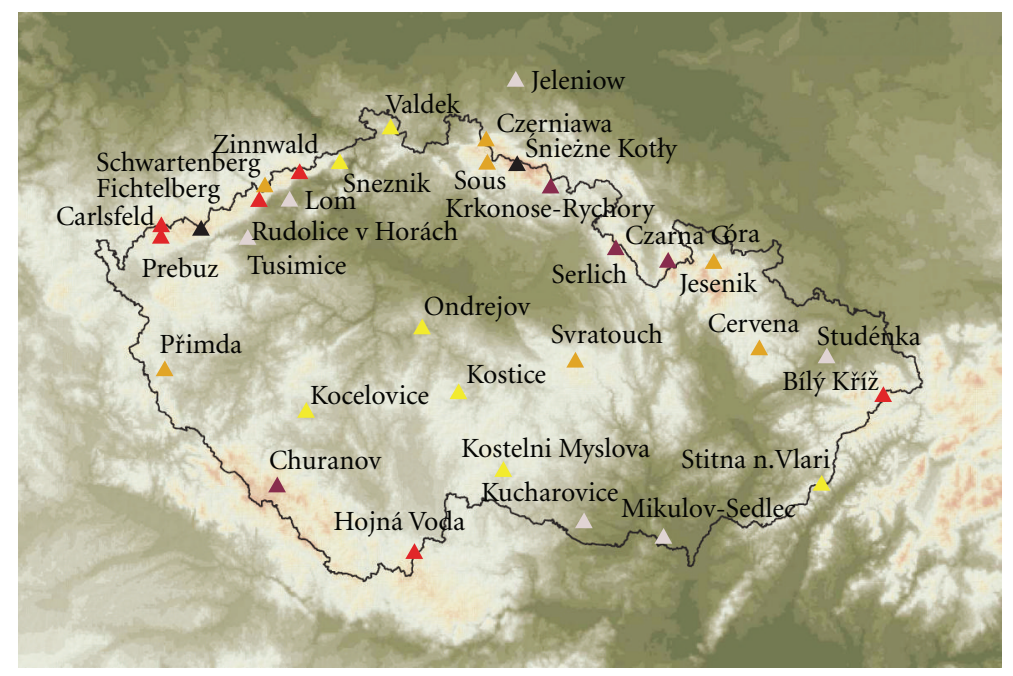
Altitude [m s. I.]
231-400
A 801-1000
$401-600$
- 1001-1200
- 601-800
\ 1201-1490

FIGURE 1: Sites with online monitoring of ambient $\mathrm{O}_{3}$ concentrations ranked according to altitude.

TABLE 1: Methods used for interpolation.

\begin{tabular}{|c|c|}
\hline Method & Acronym \\
\hline Interpolation of measured data by inverse distance weighting & IDW \\
\hline Interpolation of measured data by radial basis functions & RBF \\
\hline Interpolation of measured data by ordinary kriging & $\mathrm{OK}$ \\
\hline Linear regression of measured data and altitude & LR \\
\hline $\begin{array}{l}\text { Linear regression of measured data and altitude with subsequent } \\
\text { interpolation of its residuals by IDW }\end{array}$ & $\mathrm{LR}+$ res_IDW \\
\hline $\begin{array}{l}\text { Linear regression of measured data and altitude with subsequent } \\
\text { interpolation of its residuals by RBF }\end{array}$ & $\mathrm{LR}+$ res_RBF \\
\hline $\begin{array}{l}\text { Linear regression of measured data and altitude with subsequent } \\
\text { interpolation of its residuals by OK }\end{array}$ & $\mathrm{LR}+$ res_OK \\
\hline $\begin{array}{l}\text { Interpolation of mean afternoon } \mathrm{O}_{3} \text { concentration minus regression of mean } \\
\mathrm{O}_{3} \text { afternoon increment with altitude [15] }\end{array}$ & ALR \\
\hline $\begin{array}{l}\text { Interpolation of mean afternoon } \mathrm{O}_{3} \text { concentration minus regression of mean } \\
\mathrm{O}_{3} \text { afternoon increment with altitude [15] with subsequent interpolation of } \\
\text { its residuals by IDW }\end{array}$ & $\mathrm{ALR}+$ res_IDW \\
\hline $\begin{array}{l}\text { Interpolation of mean afternoon } \mathrm{O}_{3} \text { concentration minus regression of mean } \\
\mathrm{O}_{3} \text { afternoon increment with altitude [15] with subsequent interpolation of } \\
\text { its residuals by RBF }\end{array}$ & $\mathrm{ALR}+$ res_RBF \\
\hline $\begin{array}{l}\text { Interpolation of mean afternoon } \mathrm{O}_{3} \text { concentration minus regression of mean } \\
\mathrm{O}_{3} \text { afternoon increment with altitude [15] altitude with subsequent } \\
\text { interpolation of its residuals by OK }\end{array}$ & ALR + res_OK \\
\hline
\end{tabular}

where $\Phi(x)$ is a specific RBF function, $d_{0 i}$ is the distance between the interpolated point and the $i$ th point with measurement, $w_{1}, \ldots, w_{n+1}$ are the weighting parameters, and $n$ is the number of surrounding sites used for interpolation.

Although calculation of the RBF and estimation of its parameters is rather complicated, the computation is simple and fast. The parameters $w_{1}, \ldots, w_{n+1}$ are obtained from the system of equations given by

$$
\begin{gathered}
\sum_{j=1}^{n} w_{j} \Phi\left(d_{i j}\right)+w_{n+1}=Z\left(s_{i}\right), \quad i=1, \ldots, n, \\
\sum_{j=1}^{n} w_{j}=-w_{n+1} .
\end{gathered}
$$


A more detailed description is given by [36]. Coyle et al., 2002, [15] applied this interpolation technique within his approach for ambient $\mathrm{O}_{3}$ mapping for Great Britain.

(C) Ordinary Kriging. Ordinary kriging is a geostatistical interpolation method. It considers the statistical model:

$$
Z(s)=\mu+\varepsilon(s), \quad s \in D,
$$

where $\mu$ represents the constant mean structure of the concentration field, $\varepsilon(s)$ is a smooth variation plus measurement error (both zero-mean), and $D$ is the examined area.

The interpolation is performed according to the equation

$$
\hat{Z}\left(s_{0}\right)=\sum_{i=1}^{n} \lambda_{i} Z\left(s_{i}\right), \quad \sum_{i=1}^{n} \lambda_{i}=1,
$$

where $\hat{Z}\left(s_{0}\right)$ is the interpolated value of concentration in the point $s_{0}, Z\left(s_{i}\right)$ is the measured value of concentration in the $i$ th point, $i=1, \ldots, n, n$ is the number of surrounding sites used for interpolation, and $\lambda_{1}, \ldots, \lambda_{n}$ are the weights assumed based on a semivariogram.

The weights $\lambda_{i}$ are derived from a semivariogram $\gamma(\cdot)$ in order to minimize the mean square error. The explicit calculation is achieved by the system of equations given by

$$
\begin{gathered}
-\sum_{j=1}^{n} \lambda_{j} \gamma\left(s_{i}-s_{j}\right)+\gamma\left(s_{0}-s_{i}\right)-m=0, \quad i=1, \ldots, n, \\
\sum_{i=1}^{n} \lambda_{i}=1 .
\end{gathered}
$$

Kriging is a commonly used standard method. For construction of an $\mathrm{O}_{3}$ surface, it was used, for example, by [38-40].

\subsubsection{Interpolation Methods Using Both Measured and Auxil-} iary Data. The methods described in Section 2.2.1 were used only for the interpolation of the measured $\mathrm{O}_{3}$ concentrations. Apart from these methods, there are others using wellcorrelated physical relationships between concentrations and other characteristics, for which more complex spatial information is known. The simplest approaches are the linear regression models without spatial interpolation; more complicated are different combinations of linear regression and spatial interpolation.

(A) Linear Regression Model without Spatial Interpolation. The basic linear regression model equation considered is

$$
Z(s)=c+a_{1} * X_{1}(s)+a_{2} * X_{2}(s)+\cdots,
$$

where $X_{i}(s)$ are different supplementary parameters at the point $s$, for $i=1,2, \ldots, c$, and $a_{1}, a_{2}, \ldots$, are the parameters of the linear regression model.

In our case, altitude is used as the auxiliary parameter.

(B) Linear Regression Model Followed by the Spatial Interpolation of Residuals. The interpolation is estimated according to

$$
\hat{Z}\left(s_{0}\right)=c+a_{1} \cdot X_{1}\left(s_{0}\right)+a_{2} \cdot X_{2}\left(s_{0}\right)+\cdots+\eta\left(s_{0}\right),
$$

where $\hat{Z}\left(s_{0}\right)$ is the estimated value of the $\mathrm{O}_{3}$ concentration at the point $s_{0}, X_{1}\left(s_{0}\right), X_{2}\left(s_{0}\right), \ldots, X_{n}\left(s_{0}\right)$ are the $n$ number of individual auxiliary variables at the point $s_{0}, c, a_{1}, a_{2}, \ldots, a_{n}$ are the $n$ selected parameters of the linear regression model calculated at the points of measurement, and $\eta(s)$ is the spatial interpolation of the residuals of the linear regression model at the points of measurement.

The output of a dispersion model, altitude, meteorological variables (temperature, relative humidity, global radiation) may be among the auxiliary characteristics. For preparing an $\mathrm{O}_{3}$ surface, this method was used, for example, by Loibl et al., 1994 [41], who used relative altitude as the auxiliary characteristics, Horálek et al., 2008 [42], who used model EMEP, altitude, and global radiation as the auxiliary characteristics, and Abraham and Comrie, 2004 [43].

In this study we used the altitude as the sole auxiliary characteristic. The major reason was that preliminary analysis of our data showed the best association between $\mathrm{O}_{3}$ concentrations and altitude. Inclusion of meteorological variables did not bring any further benefit to our model. The assumption of linear distribution of $\mathrm{O}_{3}$ with altitude was tested prior to the regression analysis.

Different interpolation methods, as described in Section 2.2.1, can be used for interpolation of residuals.

(C) Interpolation of Mean Afternoon Concentration Minus Regression of Mean Afternoon Increment with Altitude. Ozone concentrations show diurnal variation. Next to this, mean afternoon increment (i.e., the difference between the mean afternoon concentration and the mean whole-day concentration) is strongly related to altitude; see [15]. Coyle introduced the mapping method in which this regression relation is combined with the spatial interpolation of the afternoon concentration; that is,

$$
\hat{Z}\left(s_{0}\right)=\rho\left(s_{0}\right)-R_{\Delta}\left(s_{0}\right),
$$

where $\rho\left(s_{0}\right)$ is the spatial interpolation of the mean afternoon concentrations at the point $s_{0}$ and $R_{\Delta}\left(s_{0}\right)$ is the regression relation of the increment $\Delta$ based on altitude at the point $s_{0}$.

While Coyle uses minimum curvature function (i.e., one of the RBF function) for the interpolation of afternoon values, we use ordinary kriging, as it shows generally better results; see bellow.

(D) Interpolation of Mean Afternoon Concentration Minus Regression of Mean Afternoon Increment with Altitude Followed by the Spatial Interpolation of Residuals. The variant of the method $\mathrm{C}$ is the addition of the interpolation of its residuals to the results of this method. As for the method B, different interpolation methods as introduced under Section 2.2.1 are used.

2.3. Uncertainty of Maps. We used cross-validation analysis for the assessment of uncertainty of the map. Crossvalidation compares a value measured at a monitoring site with an estimated value based on interpolation of values measured at other sites. The root mean square error (RMSE) 
TABLE 2: RMSE values (ppb) from cross-validation: comparison for different interpolation techniques for $\mathrm{O}_{3}$ means, 2007-2008 vegetation seasons.

\begin{tabular}{|c|c|c|c|c|}
\hline & \multicolumn{4}{|c|}{ Seasonal $\mathrm{O}_{3}$ mean $(\mathrm{ppb})$} \\
\hline & 2007 & 2008 & Average & \\
\hline & 40.15 & 38.87 & 39.51 & \\
\hline \multirow{2}{*}{ Interpolation technique } & \multicolumn{4}{|c|}{ RMSE (ppb) } \\
\hline & 2007 & 2008 & Average & Ranking \\
\hline IDW & 5.23 & 4.97 & 5.10 & 11 \\
\hline $\mathrm{RBF}$ & 4.92 & 4.69 & 4.80 & 10 \\
\hline OK & 4.73 & 4.67 & 4.70 & 9 \\
\hline LR & 3.45 & 3.30 & 3.38 & 5 \\
\hline $\mathrm{LR}+$ res_IDW & 3.49 & 3.48 & 3.48 & 8 \\
\hline $\mathrm{LR}+$ res_RBF & 3.40 & 3.37 & 3.38 & 6 \\
\hline $\mathrm{LR}+$ res_OK & 3.31 & 3.15 & 3.23 & 1 \\
\hline ALR & 3.43 & 3.38 & 3.40 & 7 \\
\hline ALR + res_IDW & 3.44 & 3.22 & 3.33 & 4 \\
\hline $\mathrm{ALR}+$ res_RBF & 3.41 & 3.15 & 3.28 & 3 \\
\hline ALR + res_OK & 3.39 & 3.07 & 3.23 & 1 \\
\hline
\end{tabular}

TABLE 3: RMSE values (ppb.h) from crossvalidation: comparison for different interpolation techniques for AOT40F, 2007-2008 vegetation seasons.

\begin{tabular}{|c|c|c|c|c|}
\hline & \multicolumn{4}{|c|}{ AOT40F (ppb.h) } \\
\hline & 2007 & 2008 & Average & \\
\hline & 17570 & 15202 & 16386 & \\
\hline \multirow{2}{*}{ Interpolation technique } & \multicolumn{4}{|c|}{ RMSE (ppb.h) } \\
\hline & 2007 & 2008 & Average & Ranking \\
\hline IDW & 3695 & 3105 & 3400 & 11 \\
\hline RBF & 3556 & 3023 & 3289 & 10 \\
\hline OK & 3364 & 2961 & 3163 & 9 \\
\hline LR & 3438 & 2841 & 3140 & 8 \\
\hline LR + res_IDW & 3335 & 2897 & 3116 & 7 \\
\hline $\mathrm{LR}+$ res_RBF & 3271 & 2844 & 3058 & 6 \\
\hline $\mathrm{LR}+$ res_OK & 3169 & 2827 & 2998 & 1 \\
\hline ALR & 3222 & 2842 & 3032 & 3 \\
\hline ALR + res_IDW & 3274 & 2809 & 3041 & 4 \\
\hline ALR + res_RBF & 3254 & 2852 & 3053 & 5 \\
\hline $\mathrm{ALR}+$ res_OK & 3207 & 2850 & 3029 & 2 \\
\hline
\end{tabular}

of the map, calculated according to (10), was used as the uncertainty criterion. RMSE should be as small as possible:

$$
\mathrm{RMSE}=\sqrt{\frac{1}{N} \sum_{i=1}^{N}\left(Z\left(s_{i}\right)-\hat{Z}\left(s_{i}\right)\right)^{2}}
$$

where RMSE is the root mean square error of the whole map, $Z\left(s_{i}\right)$ is the measured concentration at the $i$ th site, $i=1, \ldots$, $N, \hat{Z}\left(s_{i}\right)$ is the concentration at the ith site estimated from concentrations measured at other sites, $i=1, \ldots, N$, and $N$ is the number of measuring sites.

\section{Results}

The RMSE values comparing the different interpolation techniques both for $\mathrm{O}_{3}$ seasonal means and AOT40F are presented in Tables 2 and 3. Considering the average from the vegetation seasons of 2007 and 2008, our results indicate that the optimal interpolation approaches are LR+res_OK and ALR+res_OK. In the case of $\mathrm{O}_{3}$ seasonal means, the rankings for both methods were exactly the same, while for AOT40F LR+res_OK slightly outperformed ALR+res_OK. All three interpolation techniques alone-IDW, RBF, and OK-gave much worse results in comparison to linear regression of 


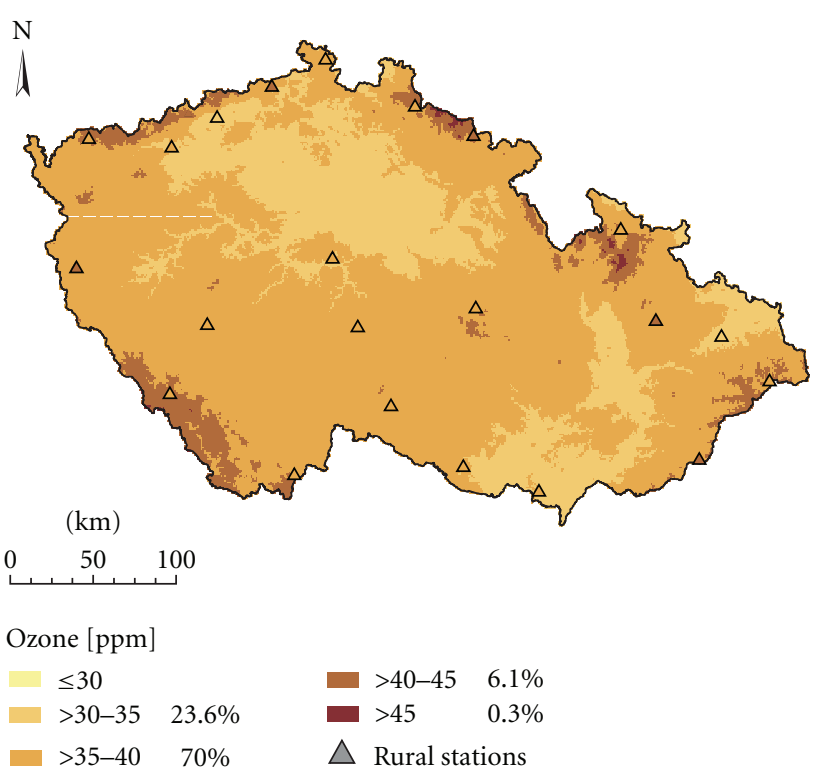

Figure 2: Spatial interpolation of mean $\mathrm{O}_{3}$ concentrations in the 2008 vegetation season ( $\mathrm{ppb}$ ), interpolation technique $\mathrm{LR}+$ res_OK, grid resolution $1 \times 1 \mathrm{~km}$.

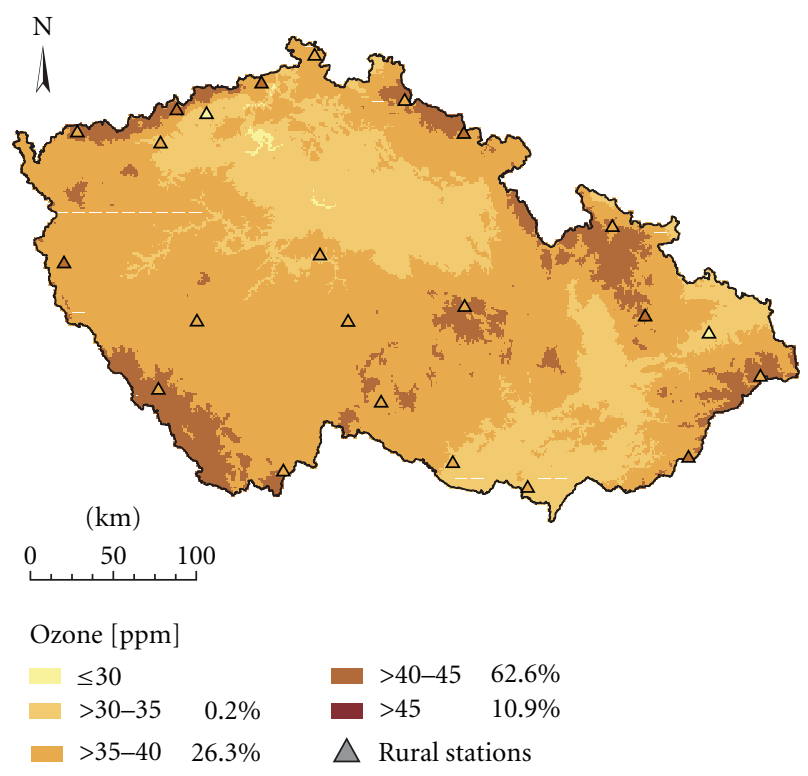

Figure 3: Spatial interpolation of mean $\mathrm{O}_{3}$ concentrations in the 2008 vegetation season (ppb), interpolation technique ALR + res_OK, grid resolution $1 \times 1 \mathrm{~km}$.

measured data and altitude with subsequent interpolation of its residuals. This held both for $\mathrm{O}_{3}$ seasonal means and AOT40F but was more pronounced for the $\mathrm{O}_{3}$ seasonal means.

The relative uncertainty of the map of mean $\mathrm{O}_{3}$ for the vegetation season was $8 \%$ for $\mathrm{LR}+$ res_OK and ALR+res_OK methods for both explored years. This is a thoroughly acceptable value. Even though the IDW method ranking indicated that it was the worst interpolation approach, the relative uncertainty of the map of mean $\mathrm{O}_{3}$ for the vegetation season was $13 \%$. In the case of AOT40F, however, the relative

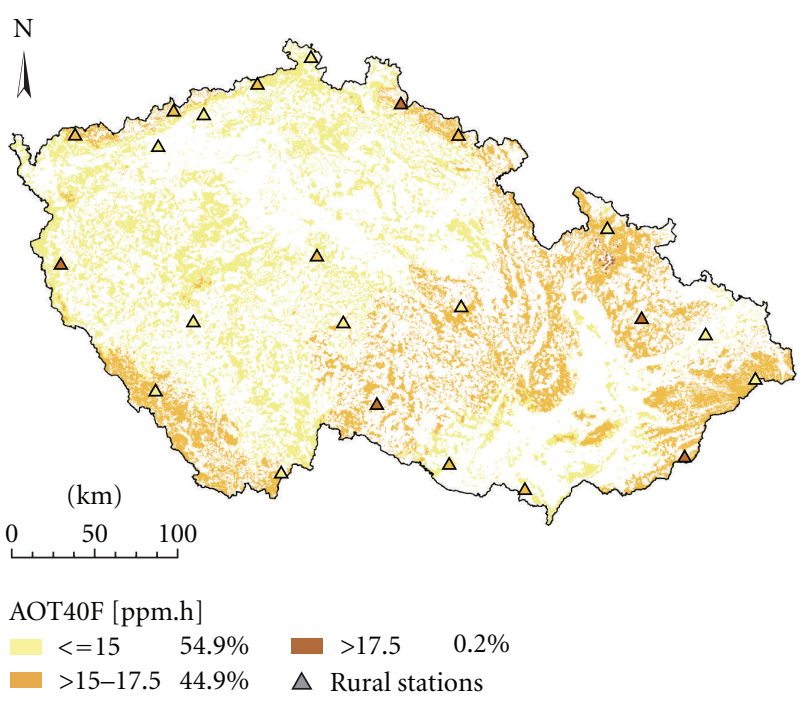

FIGURE 4: Spatial interpolation of exposure index AOT40F for the 2008 vegetation season (ppb.h), interpolation technique LR + res_OK, grid resolution $1 \times 1 \mathrm{~km}$, forested areas.

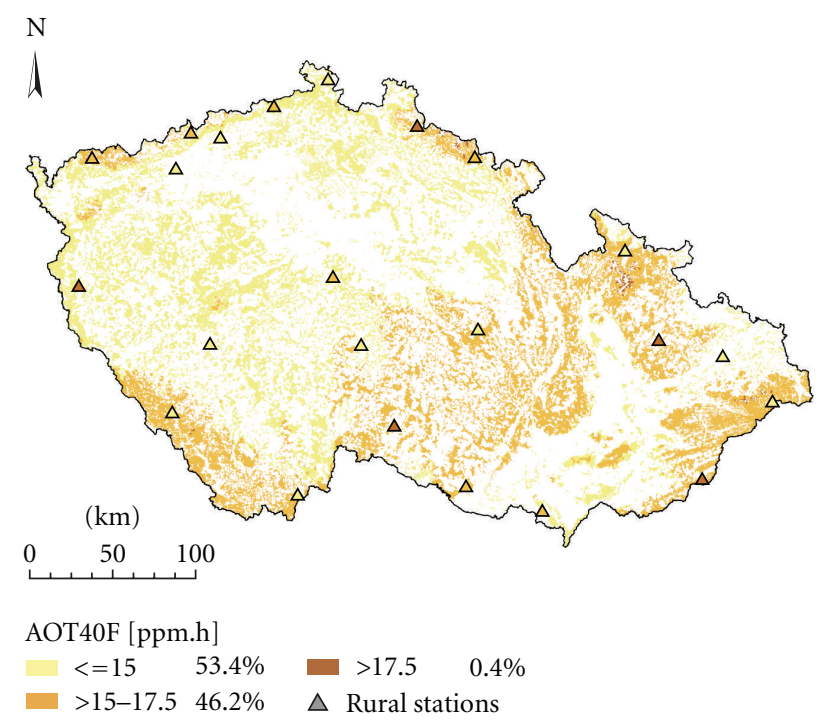

FIGURE 5: Spatial interpolation of exposure index AOT40F for the 2008 vegetation season (ppb.h), interpolation technique ALR + res_OK, grid resolution $1 \times 1 \mathrm{~km}$, forested areas.

uncertainty of the map was notably worse. For LR+res_OK, ranking as the best approach, its relative uncertainty values were $18 \%$ in 2007 and 19\% in 2008, while for IDW, assessed as the worst approach, its values were $21 \%$ for 2007 and $20 \%$ for 2008.

Figures 2 and 3 show the spatial interpolation of mean $\mathrm{O}_{3}$ concentrations in the 2008 vegetation season prepared by interpolation techniques $\mathrm{LR}+$ res_OK and ALR+res_OK which ranked best in the comparison (Table 2). The two approaches resulted in maps which are very similar and exhibited only minor differences. The same applies for Figures 4 and 5 which show the spatial variability of AOT40F values in the 2008 vegetation season prepared by interpolation techniques LR+res_OK and ALR+res_OK which ranked best in 

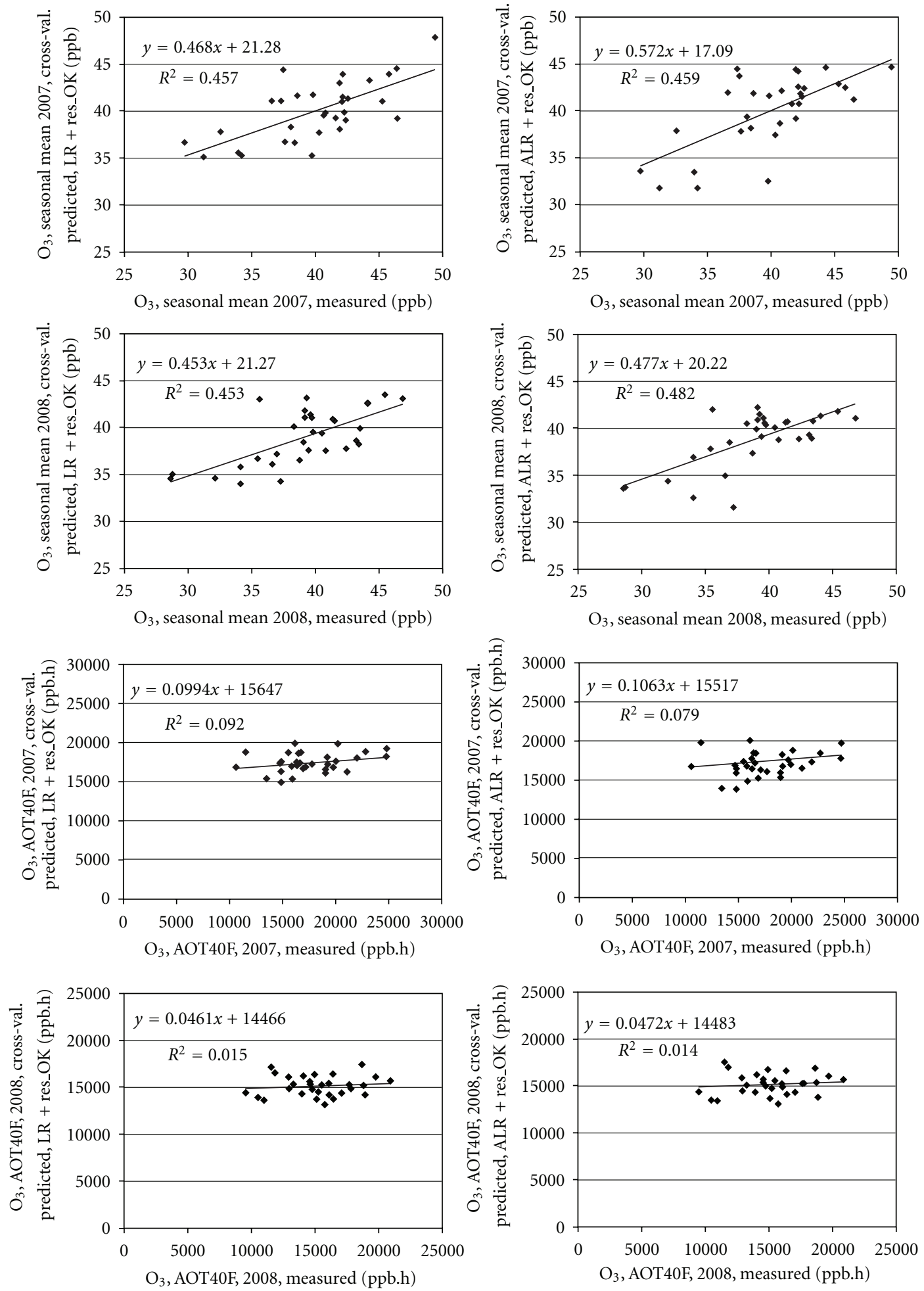

FIGURE 6: Scatter plots showing the relationship of cross-validation interpolated and measured values for the interpolation techniques LR + res_OK (left) and ALR + res_OK (right) for (a) seasonal mean $\mathrm{O}_{3}$ concentrations (b) exposure index AOT40F.

the comparison (Table 3). The relationships between the results of these two interpolation approaches are presented by scatter plots (Figure 6). Notably better results were obtained for $\mathrm{O}_{3}$ seasonal means.

\section{Discussion}

To produce a reliable air pollutant map to predict values in regions without measurements is an essential yet challenging 
task. Generally, dense monitoring networks are expensive but give a precise picture of spatial variability of a given phenomenon. Sparse sampling and monitoring networks, however, although less expensive, may miss significant spatial features of the studied phenomenon [12]. To make a real monitoring network denser, it is possible, for example, to add virtual measuring sites to improve the quality of interpolation [44]. Currently, however, no rigorous methodology for the determination of the number of monitoring sites sufficient/adequate to develop a reliable air pollutant surface is available [45]. Familiarity with the terrain and various phenomena that could affect the air pollutant concentrations and distributions are among the most important issues [12].

For mapping purposes, a number of techniques are available. There are substantial qualitative differences between the maps derived using different interpolation techniques as shown, for instance, by [46] for the maps of $\mathrm{NO}_{2}$. The assessment of performance of the different techniques is extremely important. The maps derived by different interpolation techniques may be compared and evaluated by using the objective criteria, such as cross-validation [42] when we omit one site in interpolation process and predict its values based on the rest of the sites and then compare the predicted and measured values.

Presented maps are applicable merely for rural areas. The obvious limitation of the maps is the low number of measuring sites which are unevenly distributed across the country. The spatial distribution of sites has strong historic connotations. Originally the measuring sites were located preferentially to more polluted regions, and they still remain in their original setting to observe the long-time trends.

Our results show that using the auxiliary data, in our case the dependence of $\mathrm{O}_{3}$ concentrations on altitude in particular, significantly improves the overall quality of the resulting map (see Tables 2 and 3). Meteorology was not factored into the linear regression models as the preliminary analysis of our data showed that including meteorological variables did not bring any further benefit to our model. The likely reason is fairly low number of $\mathrm{O}_{3}$ measuring sites. In near future we intend to use the Eulerian photochemical dispersion model CAMx [47] as auxiliary characteristics. The preliminary results seem to be promising. Next to this, it can be stated that the methods using ordinary kriging in its spatial interpolation part show the best results.

If we compare the two methods which ranked as the best, the LR+res_OK (i.e., linear regression of measured values with altitude followed by the interpolation of its residuals using ordinary kriging) approach slightly outperforms ALR+res_OK (i.e., the Coyle's approach [15] followed by the interpolation of its residuals using ordinary kriging) or gives comparable results. ALR+res_OK, however, is much more complicated and demanding for computation and, thus, less practical for application.

We can reasonably assume that notably worse results of mapping of AOT40F as compared to mean $\mathrm{O}_{3}$ concentration for a vegetation season (see Figure 6) are due to more random/incidental factors affecting AOT40. Moreover, exposure index AOT40 is less robust characteristic as compared to mean $\mathrm{O}_{3}$ concentrations [33].
Presented maps show the high-resolution $\mathrm{O}_{3}$ spatial patterns which can be used for assessment of $\mathrm{O}_{3}$ effects on vegetation. Exposure maps in particular are useful for indication of areas with high $\mathrm{O}_{3}$ phytotoxic potential for forests and were already used across the Czech forests earlier [26]. Spatial patterns of $\mathrm{O}_{3}$ seasonal means are useful for estimation of $\mathrm{O}_{3}$ deposition as published for the Czech coniferous and deciduous forests by [23] and for estimation of stomatal flux.

\section{Conclusions}

We developed reasonable continuous surfaces for ambient $\mathrm{O}_{3}$ vegetation season mean concentrations and AOT40F using eleven interpolation approaches. The comparison based on RMSE indicates that linear regression between measured $\mathrm{O}_{3}$ data and altitude with subsequent interpolation of its residuals outperforms the interpolation techniques IDW, radial basis functions, and ordinary kriging significantly. This holds for both $\mathrm{O}_{3}$ seasonal means and AOT40F, and, in the case of $\mathrm{O}_{3}$ seasonal means, this feature is more pronounced as compared to AOT40F. Considering all different aspects, including the results of cross-validation analysis and the demandingness of computation, linear regression of $\mathrm{O}_{3}$ data and altitude with subsequent interpolation of its residuals by ordinary kriging can be recommended as the optimal approach out of the eleven spatial interpolation techniques examined. Notably better results in mapping were obtained for mean seasonal $\mathrm{O}_{3}$ concentrations in comparison to exposure index AOT40F.

\section{Acknowledgments}

This study was funded by the Ministry of Environment of the Czech Republic MŽP (SP/1b7/189/07). The data on ambient ozone were provided by the Czech Hydrometeorological Institute. We appreciate the assistance of Linton Corbet who revised the English and commented on the final version of the paper.

\section{References}

[1] J. N. Cape, "Surface ozone concentrations and ecosystem health: past trends and a guide to future projections," Science of the Total Environment, vol. 400, no. 1-3, pp. 257-269, 2008.

[2] J. H. Seinfeldt and S. N. Pandis, Atmospheric Chemistry and Physics, Wiley-Interscience, New York, NY, USA, 1998.

[3] B. S. Felzer, T. Cronin, J. M. Reilly, J. M. Melillo, and X. Wang, "Impacts of ozone on trees and crops," Comptes RendusGeoscience, vol. 339, no. 11-12, pp. 784-798, 2007.

[4] O. N. Singh and P. Fabian, Atmospheric Ozone: A Millenium Issue, EGU Special Publication Series 1. Copernicus, Berlin, Germany, 2003.

[5] IPCC, Climate Change 2007. Synthesis Report, IPCC, Geneva, Switzerland, 2007.

[6] I. S. A. Isaksen, Ozone-Climate Interactions, Air Pollution Research Report No. 81. EC, Brussels, Belgium, 2003.

[7] A. Volz and D. Kley, "Evaluation of the Montsouris series of ozone measurements made in the nineteenth century," Nature, vol. 332, no. 6161, pp. 240-242, 1988. 
[8] J. E. Jonson, D. Simpson, H. Fagerli, and S. Solberg, "Can we explain the trends in European ozone levels?" Atmospheric Chemistry and Physics, vol. 6, no. 1, pp. 51-66, 2006.

[9] R. Vingarzan, "A review of surface ozone background levels and trends," Atmospheric Environment, vol. 38, no. 21, pp. 3431-3442, 2004.

[10] D. J. Jacob, J. H. Crawford, M. M. Kleb et al., "Transport and chemical evolution over the pacific (TRACE-P) aircraft mission: design, execution, and first results," Journal of Geophysical Research D, vol. 108, no. 20, article 8781, 2003.

[11] N. Cressie, Statistics for Spatial Data, John Wiley \& Sons, New York, NY, USA, 1993.

[12] W. Fraczek, A. Bytnerowicz, and A. Legge, Optimizing a Monitoring Network for Assessing Ambient Air Quality in the Athabasca Oil sands Region of Alberta Canada. Alpine space-Man \& Environment 7: Global Change and Sustainable Development in Mountain Regions, Innsbruck University Press, 2003.

[13] L. Wu and M. Bocquet, "Optimal redistribution of the background ozone monitoring stations over France," Atmospheric Environment, vol. 45, pp. 772-783, 2011.

[14] D. L. Peterson, "Monitoring air quality in mountains: designing an effective network," Environmental Monitoring and Assessment, vol. 64, no. 1, pp. 81-91, 2000.

[15] M. Coyle, R. I. Smith, J. R. Stedman, K. J. Weston, and D. Fowler, "Quantifying the spatial distribution of surface ozone concentration in the UK," Atmospheric Environment, vol. 36, no. 6, pp. 1013-1024, 2002.

[16] W. Fraczek, A. Bytnerowicz, and M. J. Arbaugh, "Use of geostatistics to estimate ambient ozone patterns," in Ozone Air Pollution in the Sierra Nevada-Distribution and Effects on Forests, A. Bytnerowicz, M. J. Arbaugh, and R. Alonso, Eds., pp. 215-247, Developments in Environmental Science 2, Elsevier, Amsterdam, The Netherlands, 2003.

[17] E. H. Lee, "Use of auxiliary data for spatial interpolation of ambient ozone patterns," in Ozone Air Pollution in the Sierra Nevada-Distribution and Effects on Forests, A. Bytnerowicz, M. J. Arbaugh, and R. Alonso, Eds., pp. 165-194, Developments in Environmental Science 2, Elsevier, Amsterdam, The Netherlands, 2003.

[18] H. K. Preisler and S. Schilling, "Use of nonparametric local regression to estimate surface ozone patterns over space and time," in Ozone Air Pollution in the Sierra Nevada-Distribution and Effects on Forests, A. Bytnerowicz, M. J. Arbaugh, and R. Alonso, Eds., pp. 195-214, Developments in Environmental Science 2, Elsevier, Amsterdam, The Netherlands, 2003.

[19] A. Bytnerowicz, B. Godzik, W. Fraczek et al., "Distribution of ozone and other air pollutants in forests of the Carpathian Mountains in central Europe," Environmental Pollution, vol. 116, no. 1, pp. 3-25, 2002.

[20] R. Beelen, G. Hoek, E. Pebesma, D. Vienneau, K. de Hoogh, and D. J. Briggs, "Mapping of background air pollution at a fine spatial scale across the European Union," Science of the Total Environment, vol. 407, no. 6, pp. 1852-1867, 2009.

[21] J. Horálek, B. Denby, P. de Smet et al., "Spatial mapping of air quality for European scale assessment," ETC/ACC Technical paper 2006/6, 2007, http://acm.eionet.europa.eu/docs/ ETCACC_TechnPaper_2006_6_Spat_AQ.pdf.

[22] J. Horálek, J. Fiala, P. Kurfürst, B. Denby, P. de Smet, and F. de Leeuw, Spatial assessment of PM10 and ozone concentrations in Europe (2005) EEA Technical report No 1/2009, 2009, http://acm.eionet.europa.eu/reports/EEA_TR_1_2009_Spatial AQ_assessment_2005.
[23] M. Zapletal and P. Chroust, "Ozone deposition to a coniferous and deciduous forest in the Czech Republic," Water, Air, and Soil Pollution, vol. 7, no. 1-3, pp. 187-200, 2007.

[24] I. Hůnová, "Ambient air quality for the territory of the Czech Republic in 1996-1999 expressed by three essential factors," Science of the Total Environment, vol. 303, no. 3, pp. 245-251, 2003.

[25] I. Hůnová, J. Šantroch, and J. Ostatnická, “Ambient air quality and deposition trends at rural stations in the Czech Republic during 1993-2001," Atmospheric Environment, vol. 38, no. 6, pp. 887-898, 2004.

[26] I. Hůnová, H. Livorová, and J. Ostatnická, "Potential ambient ozone impact on ecosystems in the Czech Republic as indicated by exposure index AOT40," Ecological Indicators, vol. 3, no. 1, pp. 35-47, 2003.

[27] I. Hunová, R. Novotný, H. Uhlírová et al., "The impact of ambient ozone on mountain spruce forests in the Czech Republic as indicated by malondialdehyde," Environmental Pollution, vol. 158, no. 7, pp. 2393-2401, 2010.

[28] I. Hůnová, L. Matoušková, R. Srněnský, and K. Koželková, "Ozone influence on native vegetation in the Jizerske hory Mts. of the Czech Republic: results based on ozone exposure and ozone-induced visible symptoms," Environmental Monitoring and Assessment, vol. 183, no. 1-4, pp. 501-515, 2011.

[29] EC, Directive 2008/50/EC of the European Parliament and of the Council of 21 May 2008 on ambient air quality and cleaner air for Europe, OJEC L 152, 2008.

[30] J. Fuhrer, L. Skärby, and M. R. Ashmore, "Critical levels for ozone effects on vegetation in Europe," Environmental Pollution, vol. 97, no. 1-2, pp. 91-106, 1997.

[31] UN/ECE, Mapping Manual Revision, UNECE convention on long-range transboundary air pollution, Manual on the Methodologies and Criteria for Modelling and Mapping Critical Loads and Levels and Air Pollution Effects, Risks and Trends, 2004, http://www.icpmapping.org.

[32] J. P. Tuovinen, "Assessing vegetation exposure to ozone: properties of the AOT40 index and modifications by deposition modelling," Environmental Pollution, vol. 109, no. 3, pp. 361$372,2000$.

[33] M. Sofiev and J. P. Tuovinen, "Factors determining the robustness of AOT40 and other ozone exposure indices," Atmospheric Environment, vol. 35, no. 20, pp. 3521-3528, 2001.

[34] EC, "Directive 2002/3/EC of the European Parliament and of the Council of 12 February 2002 relating to ozone in ambient air," OJEC, no. L 67, pp. 14-30, 2002.

[35] EC, "Council Decision 97/101/EC of 27 January 1997 establishing a reciprocal exchange of information and data from networks and individual stations measuring ambient air pollution within the Member States," Official Journal of the European Communities, no. L 35/14, 1997.

[36] K. Johnston, J. Ver Hoef, K. Krivoruchko, and N. Lucas, Using ArcGIS Geostatistical Analyst, Environmental Systems Research Institute, Redlands, Calif, USA, 2001.

[37] E. H. Isaaks and R. M. Srivastava, An Introduction to Applied Geostatistics, Oxford University Press, Oxford, UK, 1989.

[38] L. S. Casado, S. Rouhani, C. A. Cardelino, and A. J. Ferrier, "Geostatistical analysis and visualization of hourly ozone data," Atmospheric Environment, vol. 28, no. 12, pp. 21052118, 1994.

[39] A. S. Lefohn, H. P. Knudsen, and L. R. McEvoy, "The use of kriging to estimate monthly ozone exposure parameters for 
the Southeastern United States," Environmental Pollution, vol. 53 , no. $1-4$, pp. 27-42, 1988.

[40] A. G. Hjellbrekke, “Ozone measurements 1998," EMEP/CCCReport 5/2000, Norwegian Institute for Air Research, 2000.

[41] W. Loibl, W. Winiwarter, A. Kopsca, J. Zueger, and R. Baumann, "Estimating the spatial distribution of ozone concentrations in complex terrain," Atmospheric Environment, vol. 28, no. 16, pp. 2557-2566, 1994.

[42] J. Horálek, P. de Smet, F. de Leeuw, B. Denby, P. Kurfurst, and R. Swart, "European air quality maps for 2005 including uncertainty analysis," ETC/ACC Technical Paper 2007/7, 2008, http://acm.eionet.europa.eu/docs/ETCACC_TP_2007_7 _SpatialAQmapping2005_annual_interpolations.pdf.

[43] J. S. Abraham and A. C. Comrie, "Real-time ozone mapping using a regression-interpolation hybrid approach, applied to Tucson, Arizona," Journal of the Air and Waste Management Association, vol. 54, no. 8, pp. 914-925, 2004.

[44] A. L. Beaulant, G. Perron, J. Kleinpeter, C. Weber, T. Ranchin, and L. Wald, "Adding virtual measuring stations to a network for urban air pollution mapping," Environment International, vol. 34, no. 5, pp. 599-605, 2008.

[45] G. Hoek, R. Beelen, K. de Hoogh et al., "A review of landuse regression models to assess spatial variation of outdoor air pollution," Atmospheric Environment, vol. 42, no. 33, pp. 7561-7578, 2008.

[46] C. D. Lloyd and P. M. Atkinson, "Increased accuracy of geostatistical prediction of nitrogen dioxide in the United Kingdom with secondary data," International Journal of Applied Earth Observation and Geoinformation, vol. 5, no. 4, pp. 293-305, 2004.

[47] ENVIRON, "User s guide to the Comprehensive Air Quality model with extensions (CAMx) version 5.10," 2009, http:// www.camx.com. 

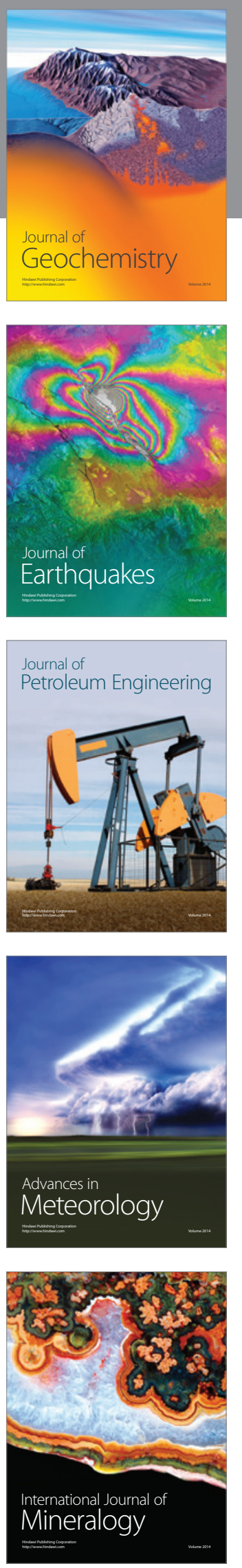
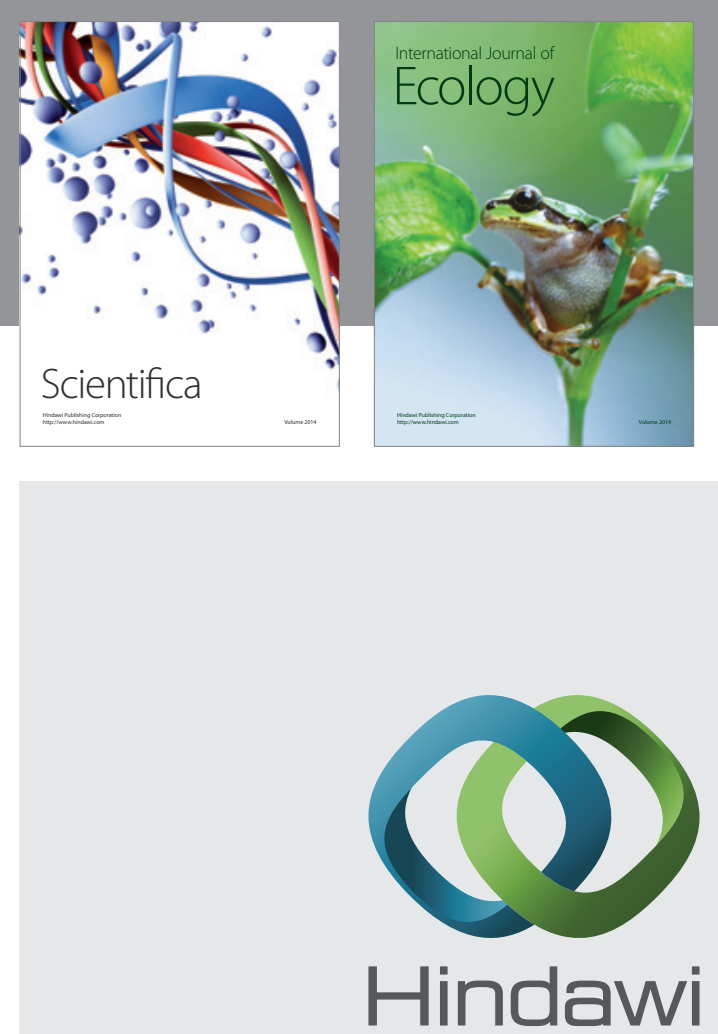

Submit your manuscripts at http://www.hindawi.com
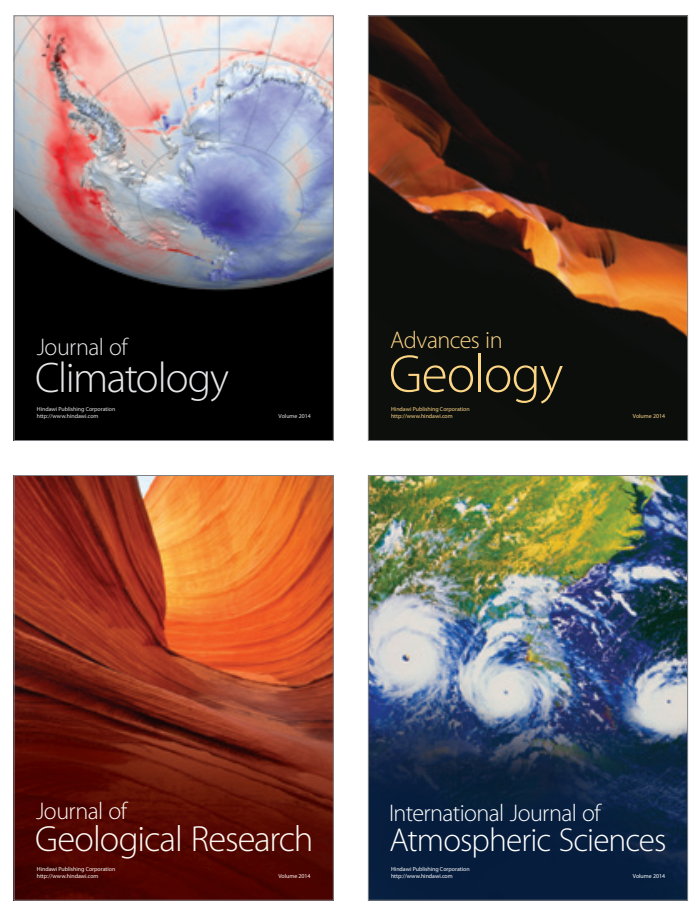
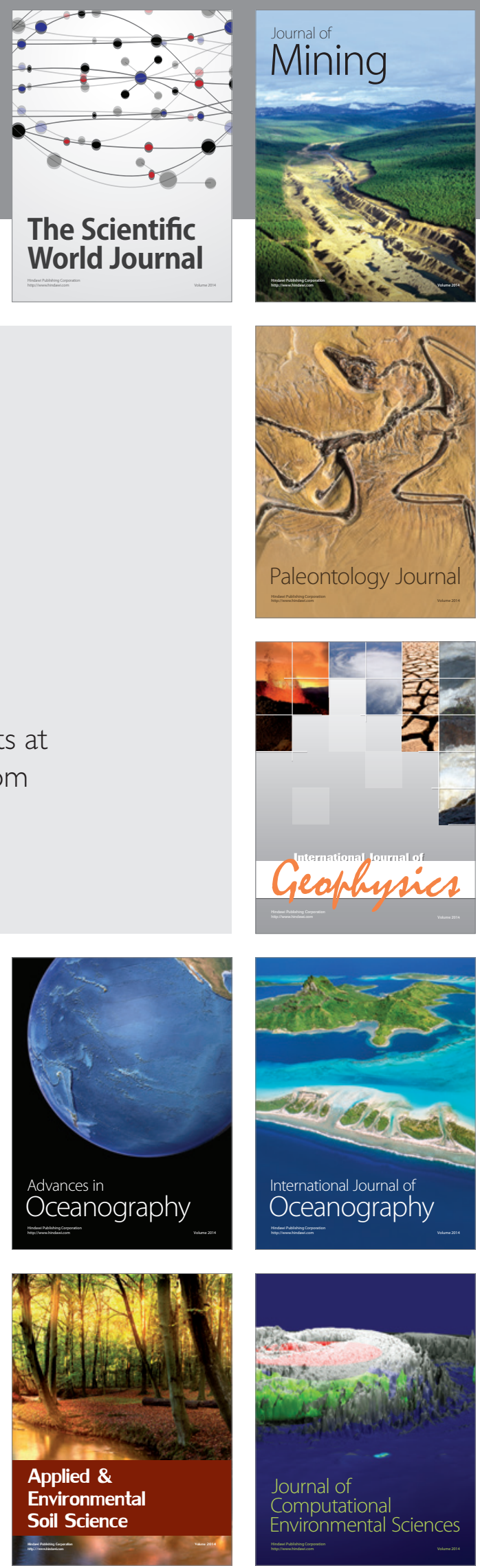